\title{
DESIGN AND MANUFACTURING OF A TERRAIN ROBOT FOR MINING ASSISTANCE AND DATA ACQUISITION
}

\author{
TRAN HUU TOAN \\ Faculty of Electronic Technology, Industrial University of Ho Chi Minh City \\ tranhuutoan@iuh.edu.vn
}

\begin{abstract}
The robot assistance in human's activities of resource developing has been brought efficient applications, especially in the condition of severe and harmful environment. Inspired by the difficulties behind the above specification requirements as well as realizing the importance and applicable capacity of this field, our paper presents the development of a terrain robot for mining support and data collection. The robot has been designed through the analysis of kinematic and dynamic properties of the terrain robot. Based on the requirements of the robot's power and the load support, the solution of mechanism, actuator for the robot have been drawn. As a contribution to terrain robotic field, we present an original prototype of Mining Assistance Terrain Robot (MATRob). During development of the MATRob, a basically control design has been developed to increase the ability of integration, and ensure real-time control performance besides a custombuilt control panel for users. The robot's efficiency has been evaluated through several simulation training tests on obstacle overcome, material determination, picture /video captures and data collection.
\end{abstract}

Keywords: Mobile Robot; Terrain Robot; Mining technology; Remote control; Human-robot interaction.

\section{INTRODUCTION}

Vietnam has relatively abundant and diverse mineral resources, including fuel mineral groups such as petroleum and coal; group of iron minerals and iron alloys such as iron, chromite and titanium; group of non-ferrous metal minerals such as bauxite, tin, copper, lead-zinc and antimony [1]. However, one of the issues raised is the effectiveness of underground mining due to the harsh environment. The underground atmosphere is often very hot and lack of oxygen, lack of ventilation. There are many toxic gases such as methane, coal dust, noise, can cause many dangerous diseases in this atmosphere. Moreover, the mining environment has areas that are difficult to access to maintain and supervise the operational system of the mine. When an accident occurs, rescue assistances are difficult and not timely [2]. According to the 2014 World Disaster Report of the International Red Cross - Red Crescent Society, from 2004 to 2013, 1,059,072 persons in the world were lost in 6,525 disasters, and it cost 1,700 billion USD. In the past 20 years, Vietnam's coal industry also has faced many accidents caused by methane explosion. For example, a methane explosion at Mao Khe Coal Company in 1999 or a serious accident caused by a water pocket at the Mong Duong coal mine in 2006 or an explosion at Khe Cham Coal Company in 2008, etc. [3].

Together with the development of science and technology, robots have being applied in all areas of life and society, bringing many significant changes to the economy. For example robotic mowers, vacuum cleaners in households; underwater robots in the deep sea; unmanned aircraft and space robots in space $[4,5,6]$; and many others. Moreover, mobile robots are increasingly investigated and developed for many purposes such as: detecting military mines, inspecting and welding underground pipelines, mobile robot operating in high radioactive environments [7]. In 
the harsh and dangerous mining environment, assistance devices have to be inspected and supervised at any instant in order to make effective and timely decisions. In order to perform these tasks, these devices must be able to move through the complex terrain of the mine, to observe images and information from the working environment such as air quality, water quality, and detailed 3D scans. These works help to supervise the status before mining, to establish the document of current mining status, as well as to update mining progress. The assistance from the devices clearly reduces mining costs and improve safety in mining process [8]. In the case of disasters, these devices can assist to find the victim and report timely. Moreover, for abandoned or fully exploited mines that human cannot access, in order to re-evaluate the environmental situation or to map at these mines, the use of the above devices is very necessary, especially mobile robots.

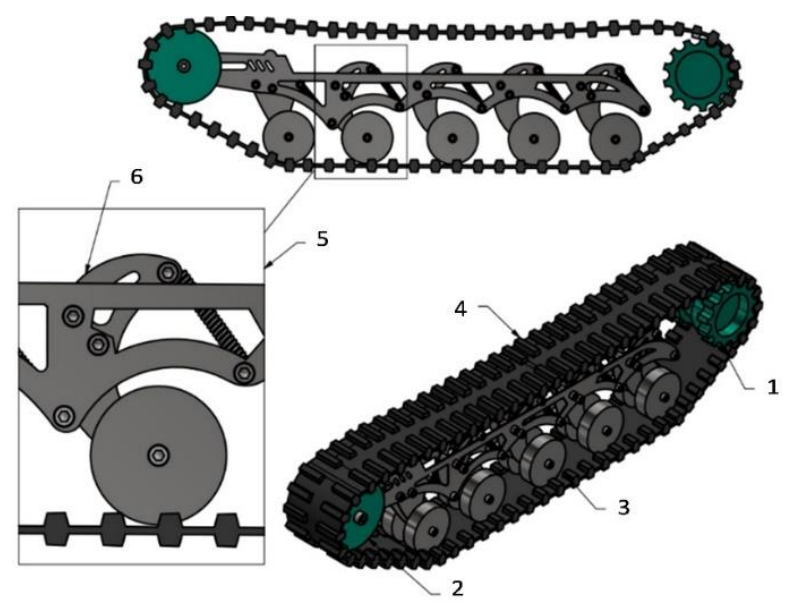

Figure 1. The structure of the MATRob wheel drive system

1: Powered sprocket wheel; 2: Idle wheel; 3: Track roller; 4: Driving belt; 5: Mechanism to increase the contact between the belt and road surface; 6: Self-adaptive bar

This paper proposes the design and manufacturing of a terrain robot for mining assistance and data collection to master the technology, bring science for production service. For the above goals and long-term orientation, the authors aim to research, manufacture and introduce the first prototype of the robot called MATRob (Mining Assistance Terrain Robot) in our university. The remainder of this paper is organized as follows; firstly, the main design results of MATRob are briefly introduced. Subsequently, we discuss how hardware is implemented on the robot. Finally, experiments will be implemented to evaluate the effectiveness of the robot on trajectory tracking, terrain ability, and data collection for mining assistance.

\section{MATROB DESIGN AND MANUFACTURING}

\subsection{Mechanical design}

a. Design of robot structure

Based on the selection of robot's actuators and the calculation of the worm gear (not presented in the scope of this paper), the MATRob standard parts have been collected and non-standard ones have been designed in detailed. For example, the overall wheel drive of robot concludes powered 
sprocket wheels; idle wheels; track roller; driving belts; self-adaptive bar as shown in Figure 1 . The 3-D design of MATRob has been described in Figure 2.
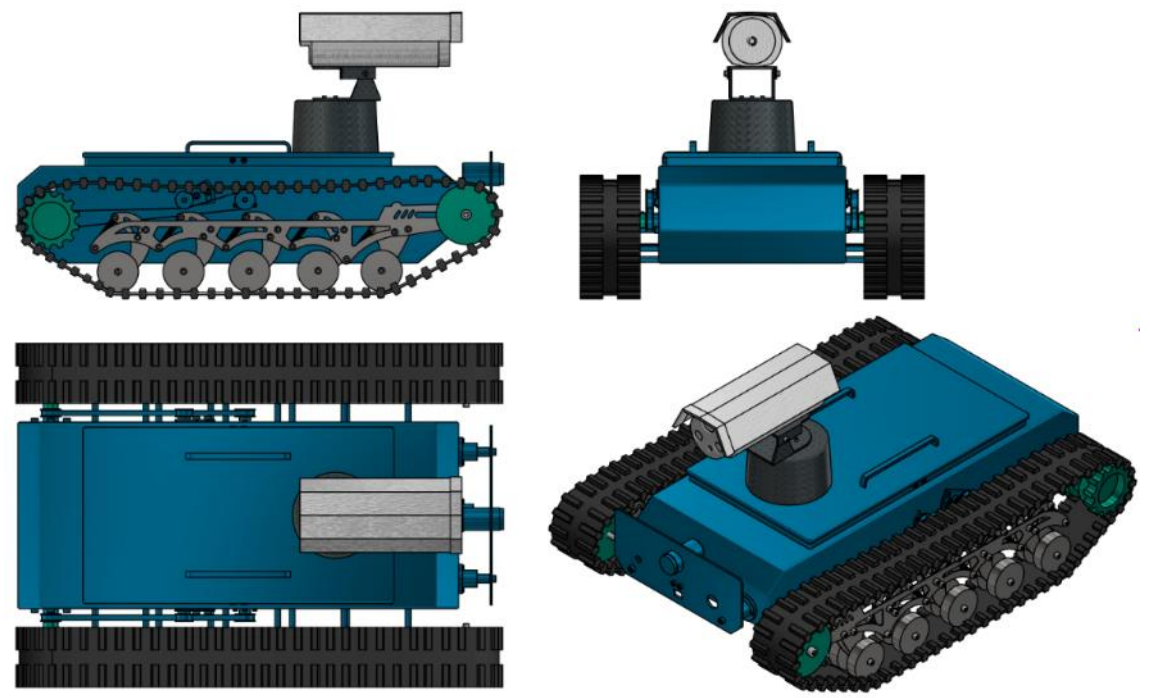

Figure 2. 3-D design of MATRob

\section{b. Design of robot structure}

As the robot moves, the gravity and thrust force of the robot fundamentally act on the selfadaptive bar as shown in Figure 3a. According to the design requirement, the robot weight is $\mathrm{P}=$ $200 \mathrm{~N}$ (i.e. load $20 \mathrm{~kg}$ ). This weight is distributed on 10 self-adaptive bars of the two driving belts. At the same time, the self-adaptive bars are also affected by the reaction forces generated by the actuator's thrust forces. The robot is designed to cross the terrain so that the bearing status of the robot is always varied. It is difficult to determine on which state these bars undergoes the largest force. Hence, the bearing capacity analysis for one of the bars is taken on the maximum gravity and thrust force of the robot. By this way, the dynamic analysis and the force diagram of the selfadaptive bar are shown in Figure $3 b$.

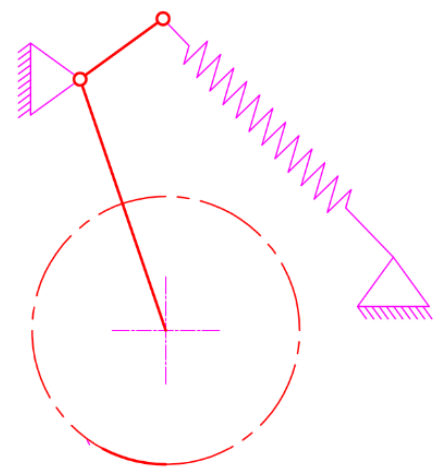

(a)

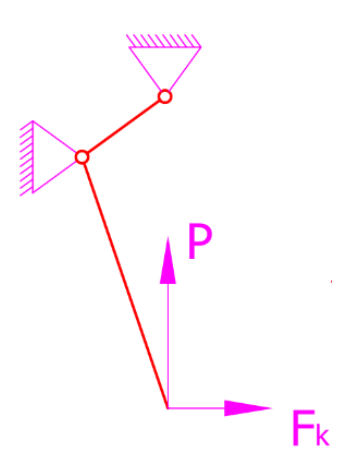

$F_{k}$

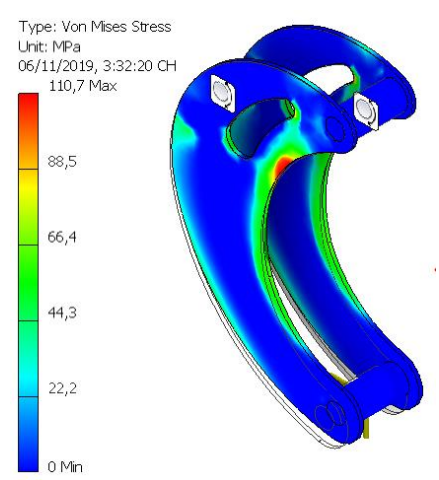

(b)

Figure 3. (a) Force diagram of the self-adaptive bar; (b) Finite analysis result on the self-adaptive bar

\subsection{Control design}

MATRob is a remote-control mobile robot system, the design of control system needs to meet special criteria such as: 
- Safety mode in power supply and safety interrupt in breakdown

- Real-time response to accurately communicate with operator's control

- Ability to collect data and evaluate the results of simulated situations

- Usability of the control panel

In addition to the above criteria, the requirements related to technology updates to put the robot into market such as: embedded system, HMI system, CPU data processing, data store and transfer from simulated situations ... are also considered for MATRob but not optimal. From these considerations, the controller hardware diagram was designed as shown in Figure 4.

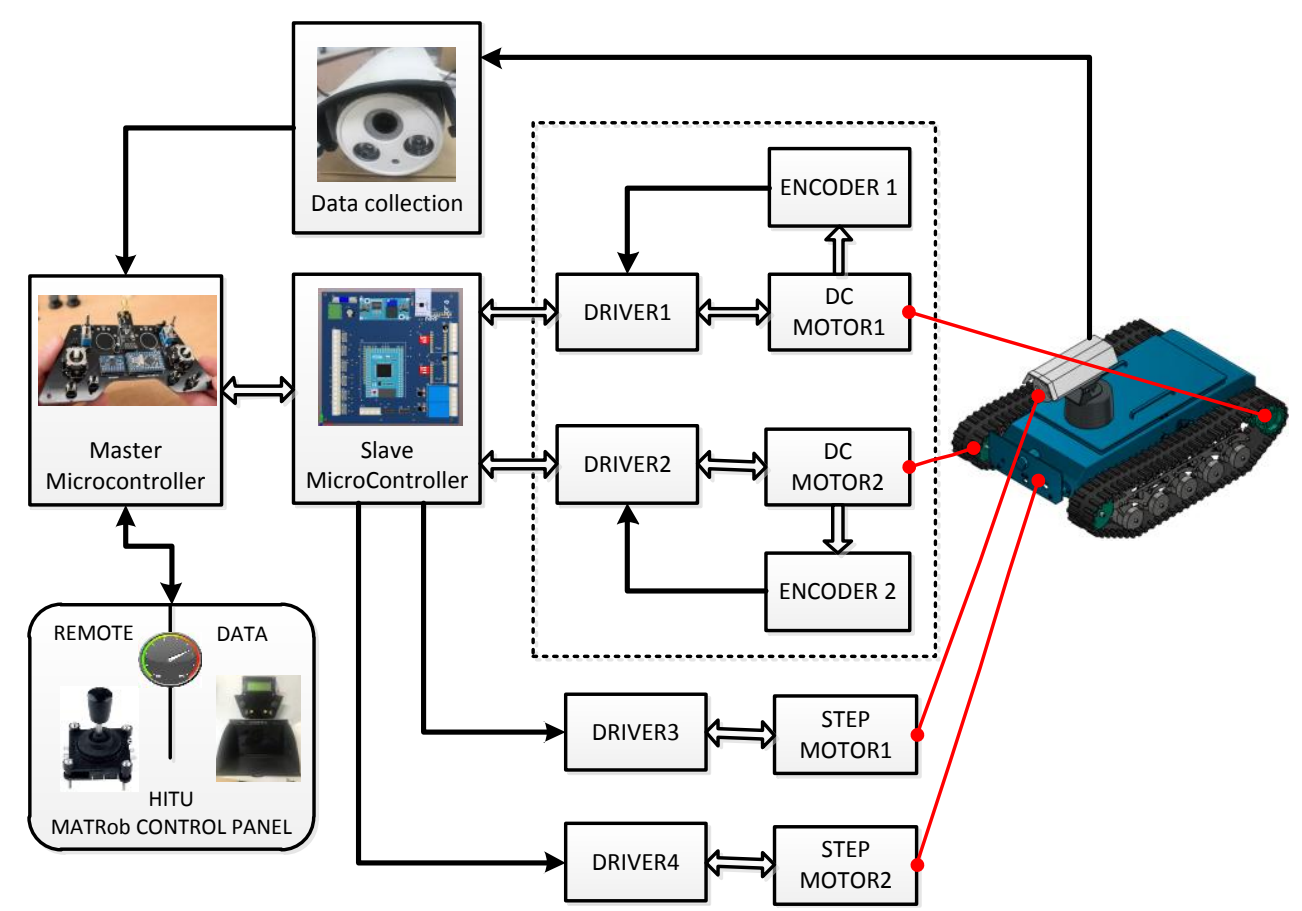

Figure 4. The MATRob's designed control hardware diagram.

\section{EXPERIMENTS AND RESULTS}

From the above design and manufacturing, MATRob is put into practice to test compared to initial aimed goals, simulated situations, and the performance response. The MATRob specifications were summarized as shown in Table 1

Table 1. The MATRob specifications after design, manufacturing, and testing. In the table, the data are obtained from design drawings and experimental measurements.

\begin{tabular}{lc}
\hline & MATRob specifications \\
\hline Parameters & Property, value (unit) \\
Degree of freedom & $4($ DOFs $)$ \\
Actuated degree of freedom & $2 / 4(\mathrm{DOFs})$ \\
Weight & $18.25(\mathrm{~kg})$ \\
Total weight (included load) & $40.0(\mathrm{~kg})$ \\
\hline
\end{tabular}




\begin{tabular}{lc}
\hline Overall size (length x width x height) & $655 \times 460 \times 385(\mathrm{~mm})$ \\
Maximum velocity & $1.2(\mathrm{~m} / \mathrm{s})$ \\
Belt length & $1420(\mathrm{~mm})$ \\
Crane mechanism's length & $100(\mathrm{~mm})$ \\
Terrain slope & $45\left(^{\circ}\right)$ \\
Remote control range & $200(\mathrm{~m})$ \\
Camera & $600 \mathrm{TTVL}($ color $)$ \\
Material & Steel - Polymer \\
DC motor power & $120(\mathrm{~W})$ \\
Maximum frequency (at the sprocket wheel) & $1 \mathrm{~Hz}$ \\
Maximum carrying load & $20(\mathrm{~kg})$ \\
\hline
\end{tabular}

\subsection{Evaluation on trajectory tracking}

Preliminary experiments have been conducted using MATRob to perform manual exercises at different operating speeds (slow, medium, fast). The operator performed maneuvers to control MATRob according to a defined manual. A certain number of experiments have been conducted ( 8 times) and 4 random ones of them have been recorded. The motion eccentricity were collected to draw the movement accuracy of MATRob. As an example, Table 2 shows the specific eccentricity results that collect the MATRob's process of supporting users to move into the workspace and to collect information. In addition, while performing the exercises according to the operator's random request, the traveled data of distance and velocity can be observed to compare and evaluate the robot's ability of accurate motion as exampled in Figure 5.

Table 2. Experimental results of control MATRob to move straight on different trials at various velocities

\begin{tabular}{|c|c|c|c|c|c|}
\hline No. & Experiment & $\begin{array}{c}\text { Traveled } \\
\text { disstance }(\mathrm{m})\end{array}$ & Velocity & $\begin{array}{l}\text { Eccentricity on } \\
\text { the first trail } \\
(\mathrm{mm})\end{array}$ & $\begin{array}{l}\text { Eccentricity on } \\
\text { the second trail } \\
\qquad(\mathrm{mm})\end{array}$ \\
\hline \multirow{3}{*}{1} & \multirow{3}{*}{ Experiment 1} & \multirow{3}{*}{50} & Slow & 53 & 52 \\
\hline & & & Medium & 58 & 61 \\
\hline & & & Fast & 74 & 68 \\
\hline \multirow{3}{*}{2} & \multirow{3}{*}{ Experiment 2} & \multirow{3}{*}{100} & Slow & 51 & 53 \\
\hline & & & Medium & 55 & 63 \\
\hline & & & Fast & 67 & 67 \\
\hline \multirow{3}{*}{3} & \multirow{3}{*}{ Experiment 3} & \multirow{3}{*}{50} & Slow & 55 & 55 \\
\hline & & & Medium & 63 & 65 \\
\hline & & & Fast & 70 & 64 \\
\hline \multirow{3}{*}{4} & \multirow{3}{*}{ Experiment 4} & \multirow{3}{*}{100} & Slow & 51 & 56 \\
\hline & & & Medium & 64 & 72 \\
\hline & & & Fast & 71 & 63 \\
\hline
\end{tabular}


At the next stage, MATRob has been conducted to track different trajectories at various operating velocities. The operator control MATRob by selecting the trajectory mode of an automatic switch. For simplicity, the chosen trajectories are a rectangle of $10 \mathrm{~m} \times 5 \mathrm{~m}$ and a circle of $5 \mathrm{~m}$ in diameter. Figure 6 shows the specific results that capture the snapshot results from the video depicting the MatRob's rectangular movement. In these experiments, the tracking trajectories of the robot was updated by the encoder and the velocities were chosen in advance.

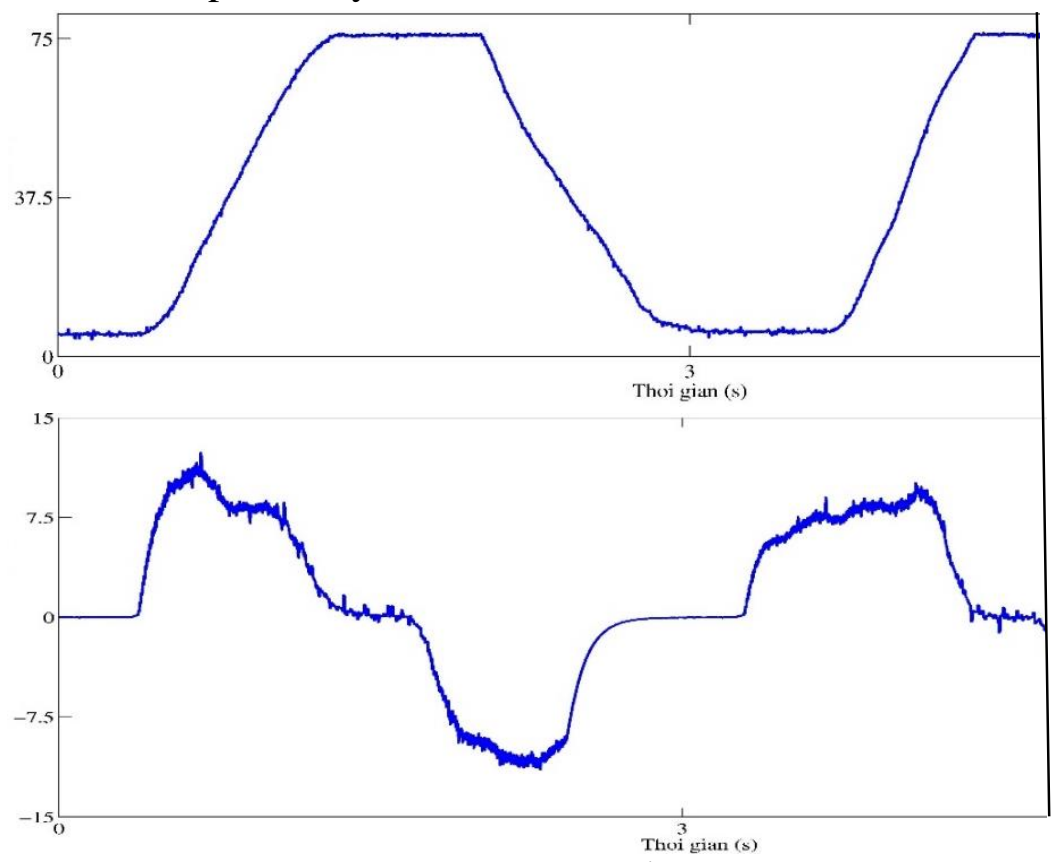

Figure 5. The traveled data of distance $(\mathrm{m})$ and velocity $\left(10^{-1} \mathrm{~m} / \mathrm{s}\right)$ in an experiment of control MATRob to move straight (the data of the measured velocity were not smoothed or filtered)

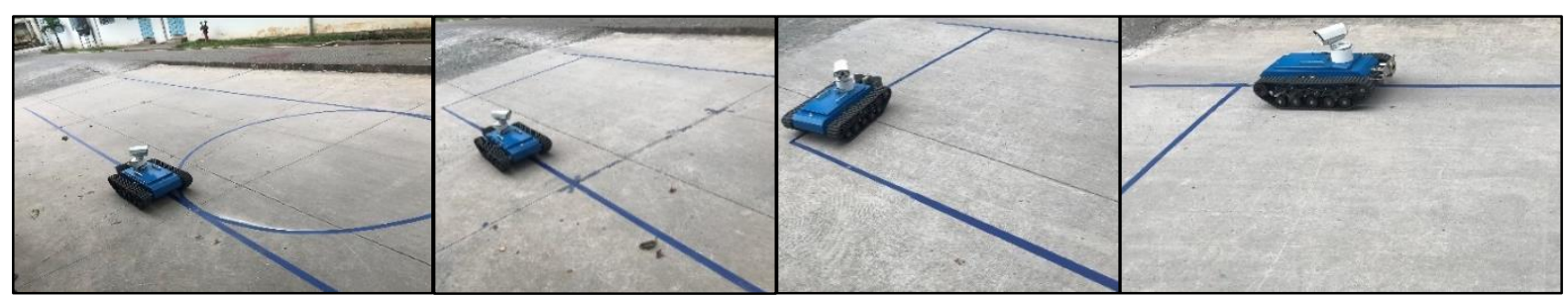

Figure 6. Snapshot collected from the process of MATRob's rectangular movement

The control results show that, for a given trajectory programmed in the salve microcontroller, MATRob tracked the trajectories accuracy with a permissible error (the tracking error does not exceed $100 \mathrm{~mm}$ ). Similar to the rectangular trajectory, Figure 7 shows the specific results that capture the snapshot results from the video depicting the MatRob's circular movement.

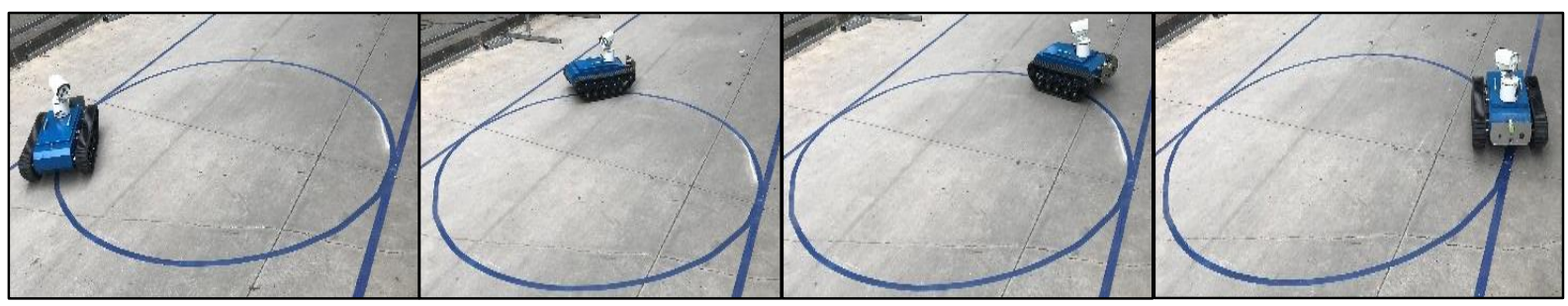

Figure 7. Snapshot collected from the process of MATRob's circular movement. 


\subsection{Evaluation on terrain ability}

In order to test the automatic function and to confirm the stable operation of MATRob, we have conducted simulated scenarios in which robot operated in difficult conditions such as grass dust, obstacle, steep hills. Operation data on the landscape in the mining environment were collected on the control screen and handle.

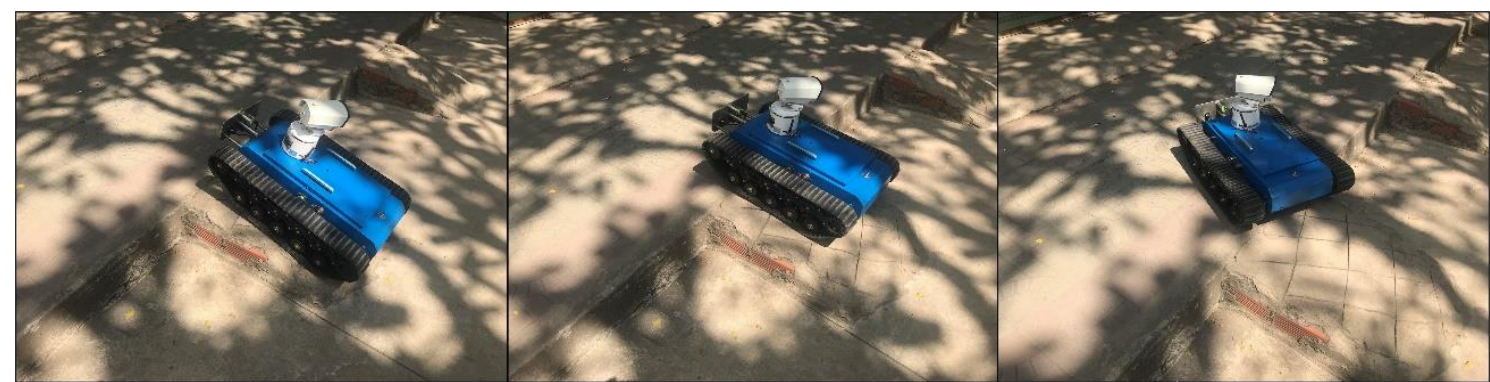

Figure 8. Snapshot collected from the process of MATRob's movement on the slope surface of 30 degree

As a demonstration of disturbance adaptive ability, experimental results in the above conditions are shown in Figures 8 and 9. Through many experiments and similarly obtained results, MATRob operated well and overcame obstacles in simulated situations with small position errors. This ensures that MATRob operates accurately and meets the primary design objectives. Similar to the experiments in flat conditions, MATRob's support in the conditions of moving through rough surfaces, gravel, or slopes were considered (Figure 10). MATRob's operation results showed a great support for the operator in situations where the robot alternate with the operator to work in the difficult environment conditions

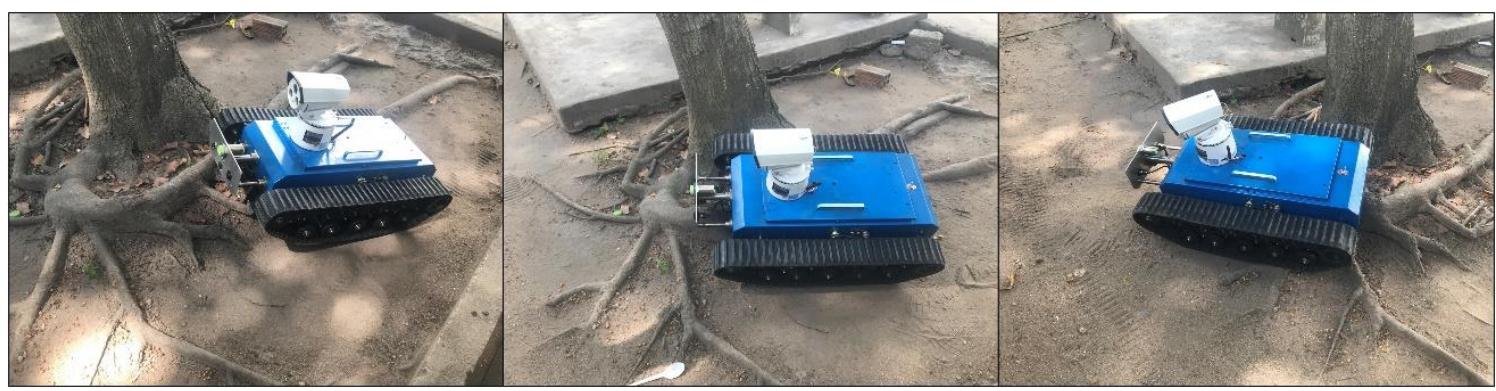

Figure 9. Snapshot collected from the process of MATRob's movement on the rough surface and obstacles

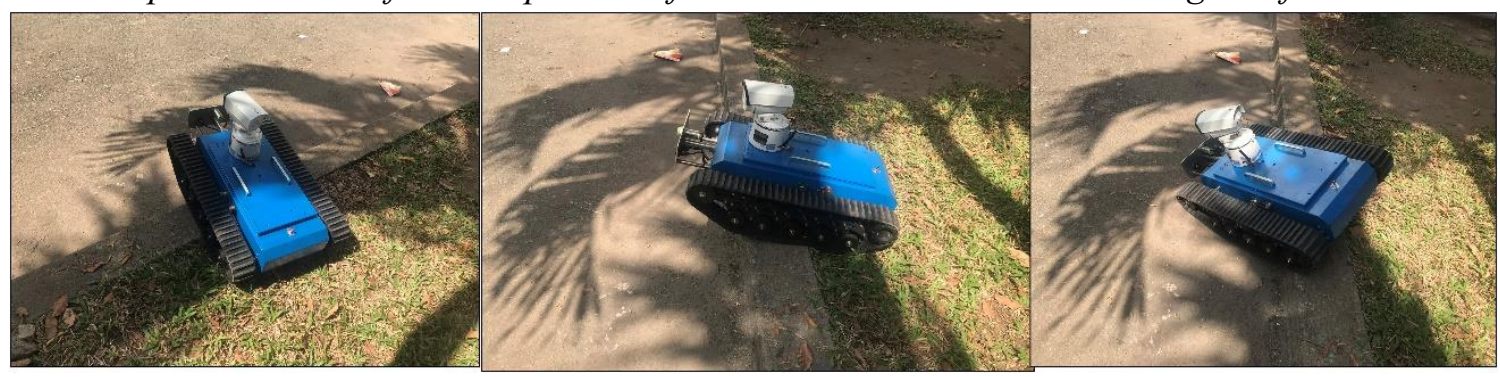

Figure 10. Snapshot collected from the process of MATRob's movement on the slope surface of 90 degree

\subsection{Evaluation on data collection for mining assistance}

After conducting trajectory tracking and terrain experiments, MATRob has been conducted to approach and identify different objects in the mine. It is assumed that there are four types of the 
material resource to identify as follows: Coal (subscripted by S1); Metal (copper, aluminum, iron) (subscripted by S2); Magnetic (magnet) (subscripted by S3); Plastic/carton (subscripted by S4); as shown in Figure 11.

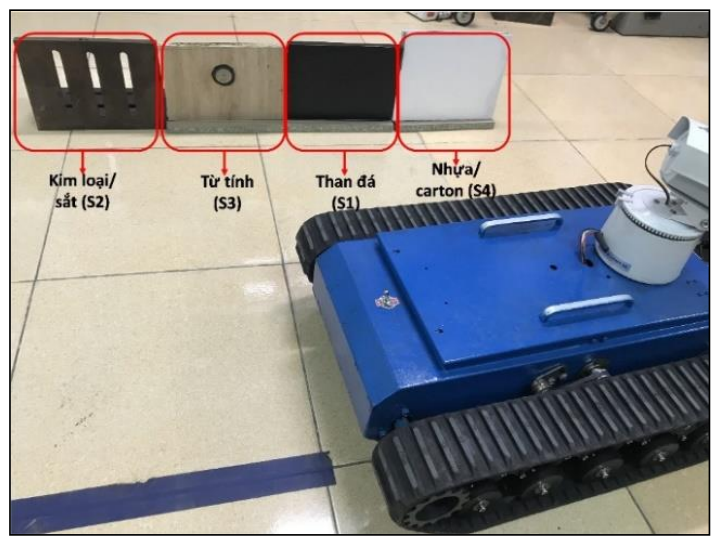

Figure 11. Material resources have been stimulated to identify by MATRob

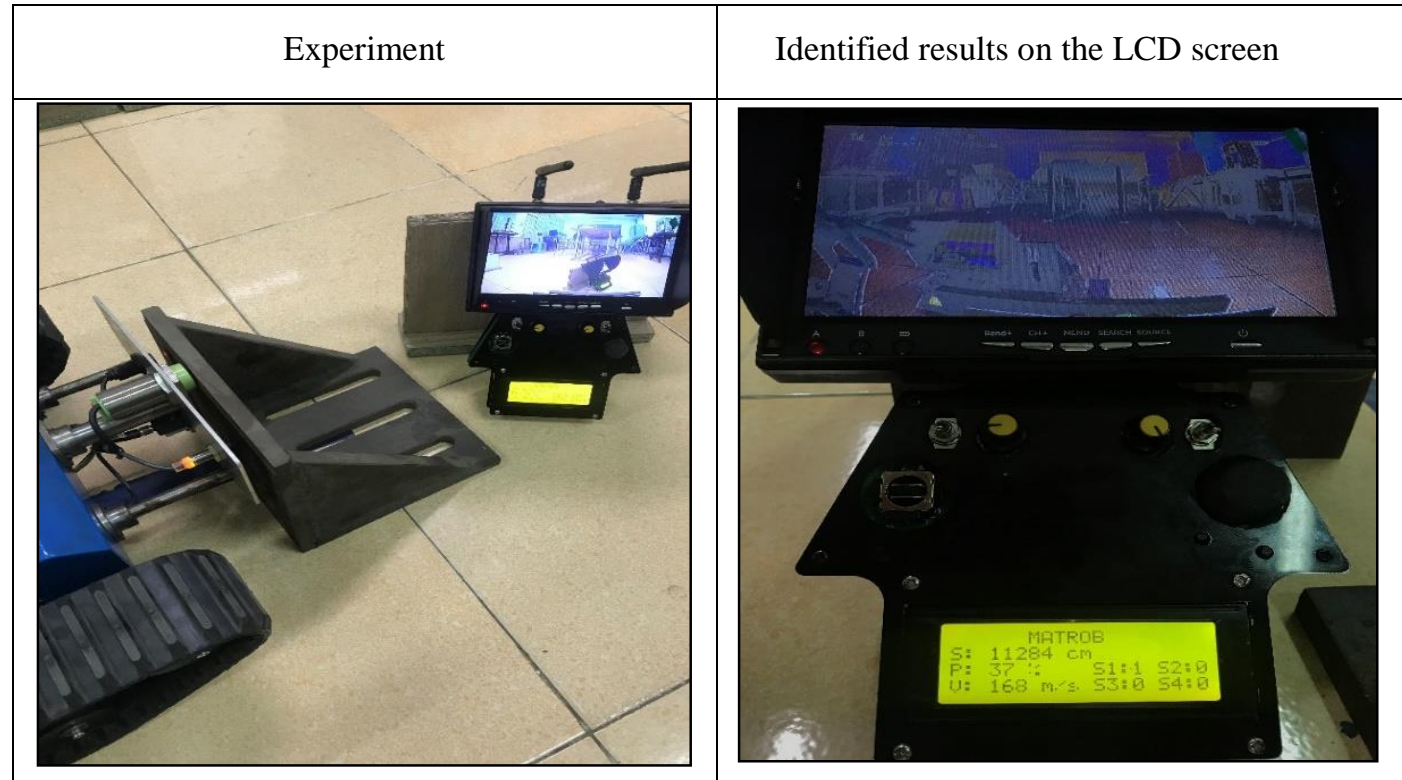

Figure 12. The simulated experiments to identify the metal object

The simulated situation is that the operator control MATRob follow a favorable direction and overcomes obstructed terrains. After that MATRob is controlled to detect one of the above simulated resources. The detected results of the material are collected by the master microcontroller which then sends the data to the slave one displayed on the LCD screen. These experiments proved MATRob's ability to assist in material detection of each simulated situation. Figure 12 shows the specific results collected from MATRob's operation in the data collection of mining support.

\section{CONCLUSIONS AND FUTURE WORKS}

The results of the verification of operation modes through repeated experiments have demonstrated that MATRob can operate stably and safely and can assist its operator in the situations when moved in difficult terrain and identified the simulated objects of the mining 
environment. Through the obtained results, the operator basically received the collected data and the moved direction from MATRob. In the normal terrain control mode, the results in $100 \%$ percentage of situations when MATRob was remote-controlled in the accuracy position and speed. Meanwhile, this percentage decreases gradually when the speed of the robot is increased and the terrain is more slope and complex.

These changes demonstrates the manufacturing errors, control errors, and friction sufficiently affected MATRob when moving at high frequency or on complex trajectories which are out of design. Similarly, the experimental results when MATRob operated difficult conditions such as the rough surface and terrain obstacles as presented above have been summarized in order to extract operation guidelines that assure a stable implementation of the control system. Similarly, we have the result of a general comparison when operating MATRob with steep terrain and bushes, gravel. In general, the MATRob system has operated stably with relatively high reliability.

However, these results only partially meet the requirements of the simulated situations, hence the limitations of the MATrob's design and manufacturing have been drawn after conducting the experiments. The motion range as well as the simulated situations of MATRob have not met all the actual situations in the mining environment, thus it is limited to apply MATRob for the environments with many more uncertain factors. The control panel is incomplete due to hardware limitations in data collection of the central microcontroller. In addition, the performed experiments are not sufficient and the number of the simulated situations for mining is not high. Hence the assessment database on the ability of the robot to trajectory tracking, terrain overcoming, and materials identification is herein not rich enough information. In the case of encountering large obstacles or being out of motion range, the mechanisms of MATRob are not flexible enough to overcome.

\section{REFERENCES}

[1] Lưu Huỳnh. Thực trạng về tình hình xuất nhập khẩu của nền kinh tế Việt Nam hiện nay và giải pháp, Báo cáo Khoa học tại Khoa Quản trị kinh doanh - Trường Đại học Kinh tế Kỹ thuật Công nghiệp, 2006

[2] Balla Kalyan, Ch. S. N. Murthy. Mine Rescue Robot System - A Review. Dept. of Mining Engineering, National Institution of Technology Karnataka, Mangalore - 575025, India

[3] Tổng hội địa chất Việt Nam. Báo cáo nghiên cứu, đánh giá “Thực trạng về quản lý khai thác và sử dụng tài nguyên khoáng sản Việt Nam”, 2011.

[4] Kasprzyczak, S. Trenczek and M. Cader. Robot for Monitoring Hazardous Environments as a Mechatronic Product. Journal of Automation, Mobile Robotics \& Intelligent Systems . Vol. 6, Issue 4, pp. 57-64, 2012

[5] W. Wang, W. Dong, Y. Su, D. Wu and Z. Du. Development of Search-and-rescue Robots for Underground Coal Mine Applications. Journal of Field Robotics, vol. 31, no. 3, 2014.

[6] Health and Safety. Rail track and associated equipment for. Health and Safety Executive, London, 2007.

[7]. Maria Isabel Ribeiro. Introduction mobile robots. Course Handouts All rights reserved, March 2002.

[8] [7] R. R. Murphy, J. Kravitz, K. Peligren, J. Milward and J. Stanway. Preliminary Report: Rescue Robot At Crandall Canyon, Utah, Mine Disaster. IEEE International Conference on Robotics and Automation, Pasadena, 2008 
[9] L. Bruzzone and G. Quaglia. Locomotion systerms for ground mobie robots in unstructured environments. University of Genoa, Italy, 2012

\title{
THIẾT KẾ, CHẾ TẠO ROBOT VƯợT ĐỊA HÌNH HỖ TRỢ KHAI THÁC KHOÁNG SẢN VÀ THU THẬP DŨ̃ LIỆU
}

\author{
TRÀN HỬU TOÀN \\ Khoa Công Nghệ Điện Tủ, truờng Đại Học Công Nghiệp Thành phố Hồ Chí Minh \\ tranhuutoan@iuh.edu.vn
}

Tóm tắt. Sự hỗ trợ từ Robot vào các hoạt động khai thác của con người đã và đang mang lại nhiều ứng dụng hiệu quả, đặc biệt trong những điều kiện môi trường khắc nghiệt, độc hại. Nhận thức được tầm quan trọng, những thách thức về học thuật cũng như xu hướng phát triển của các loại robot vượt địa hình, bài báo này trình bày việc nghiên cứu, thiết kế và chế tạo một mẫu robot vượt địa hình hỗ trợ dò tìm khoáng sản và thu thập dữ liệu. Những nghiên cứu ban đầu về đặc tính động học của các loại robot di động giúp cho chúng tôi có những cơ sở để phân tích đặc điểm và xác định các yêu cầu thiết kế. Dựa vào những yêu cầu về mặt công suất và hỗ trợ tải, các phương án truyền động và các lựa chọn cơ cấu, nguồn truyền động được đưa ra, chúng tôi phát triển một nguyên mẫu của Robot địa hình có tên gọi là MATRob (Mining Assistance Terrain Robot) với các bản vẽ thiết kế, chế tạo và tiến hành gia công nguyên mẫu của Robot. Để MATRob làm việc và thao tác hỗ trợ thu thập dữ liệu trong khai thác khoáng sản, các thiết kế điều khiển và lập trình cho robot MATRob được thực hiện dựa trên nền tảng chế độ điều khiển thời gian thực, kèm theo một bảng điều khiển các chế độ làm việc và màn hình HMI cho người sử dụng. Robot được đánh giá về hiệu quả ứng dụng thông qua các thí nghiệm giả lập về vượt địa hình, xác định vật liệu, thu thập hình ảnh và dữ liệu về robot.

Từ khóa. Robot di động; Robot địa hình; Khai thác khoáng sản; Điều khiển từ xa; Tương tác người-máy 